\title{
Droplet-vitrification cryopreservation of Tulipa tarda Stapf. apical meristems
}

\author{
Małgorzata Maślanka ${ }^{11} \cdot$ Agnieszka Szewczyk ${ }^{22}$
}

Received: 28 May 2020 / Accepted: 6 August 2020 / Published online: 16 August 2020

(c) The Author(s) 2020

\begin{abstract}
The present study provides an efficient cryopreservation protocol for Tulipa tarda cultured in vitro. Apices were excised from bulblets cultivated on MS medium, supplemented with 60 or $90 \mathrm{~g} \mathrm{l}^{-1}$ sucrose. Half of the bulblets were subjected to a cold treatment at $5{ }^{\circ} \mathrm{C}$ for 10 weeks, before exposure of the apices to loading solution (LS) and plant vitrification solution 2 (PVS2). Ten weeks after rewarming and culture on recovery medium, $100 \%$ regrowth rates were obtained for cold treated explants cultured on $60 \mathrm{~g} \mathrm{l}^{-1}$ sucrose after 30 and $60 \mathrm{~min}$ exposure to PVS2. Cold treatment significantly improved the recovery rates of most of the cryopreserved apical meristems while an enrichment of the culture medium with higher sucrose concentration $\left(90 \mathrm{~g} \mathrm{l}^{-1}\right)$ did not improve regrowth of the apices.
\end{abstract}

\section{Key message}

Cryopreservation based on droplet-vitrification technique allows for successful plant regeneration from apical meristem of Tulipa tarda.

Keywords Tulip $\cdot$ Cryoconservation $\cdot$ Apices $\cdot$ Cold treatment

\section{Abbreviations}

LN Liquid nitrogen

LS Loading solution

PVS Plant vitrification solution

RS Recovery solution

Tulipa tarda is a plant with early-blooming and multiflowered stems originally native to Central Asia, but has since become an economically-important plant used in landscaping. In natural condition, there is high diversity of $T$. tarda, due to its propagation by seeds (Botschantzeva 1982). Field collections of the tulip are expensive to maintain and

Communicated by M. Angeles Revilla

Małgorzata Maślanka ${ }^{1}$

m.maslanka@urk.edu.pl

1 Department of Ornamental Plants and Garden Art, University of Agriculture in Kraków, 29 Listopada 54 Avenue, 31-425 Kraków, Poland

2 Department of Pharmaceutical Botany, Jagiellonian University Medical College, Medyczna 9 Street, 30-688 Kraków, Poland vulnerable to pathogens and natural disasters. Due to risks of contamination and somaclonal variation, in vitro collections are not also considered to be a $100 \%$ safe method germplasm conservation (Panis and Lambardi 2006). Cryopreservation is so far the best available method for the longterm conservation of plant genetic resources, especially for vegetative propagated species, for which seed banking is not an option (Gonzáles-Benito et al. 2004; Keller et al. 2008; Li et al. 2019). Cryopreserved collections are very important for plant breeding (Reed 2017) and production of pathogen-free plants (Wang et al. 2009). Cryoconservation is possible because metabolic activity of cells in liquid nitrogen $(\mathrm{LN})\left(-196{ }^{\circ} \mathrm{C}\right)$ is arrested and plant material can be stored for extended lengths of time without risk of alterations (Engelmann and Dussert 2013). Among various available cryopreservation methods, droplet freezing technique (Schäfer-Menuhr et al. 1997) combined with vitrification (Sakai et al. 1990) resulting in droplet vitrification proved to be an efficient technique for long-term conservation of plant genetic resources (Kim et al. 2007; Sant et al. 2008; Pawłowska and Szewczyk-Taranek 2015), also for bulbous monocots like: Lilium (Chen et al. 2011; Yin et al. 2014; Urbaniec-Kiepura and Bach 2017; Li et al. 2019), Galanthus (Maślanka et al. 2013), Narcissus (Maślanka et al. 2016). 
To date, tulip cryopreservation was reported once with a maximum of 40\% regeneration (Maślanka and Bach 2013).

The experiments were conducted using Tulipa tarda Stapf. apices, obtained from an in vitro collection at the University of Agriculture in Kraków (Poland). The cultures were initiated in January 2017 from bulb scales and cultured on solid MS (Murashige and Skoog 1962) medium, supplemented with 60 or $90 \mathrm{~g} \mathrm{l}^{-1}$ sucrose in the dark at $20 \pm 2{ }^{\circ} \mathrm{C}$. After 10 weeks, development of adventitious bulblets was observed, on both sucrose concentration. These bulblets were multiplied on media with 60 and $901^{-1}$ sucrose, respectively, in the same culture conditions. Eight months after initiation of the cultures, half of all bulblets were subjected to cold conditions at $5{ }^{\circ} \mathrm{C}$ for 10 weeks prior to cryopreservation.

The droplet-vitrification procedure was based on the method of Panis et al. (2005). The apical meristems (Fig. 1a), excised from the cold treated and non-cold treated bulblets, from both sucrose concentration, were immersed in LS, containing $2 \mathrm{~m}$ glycerol and $0.4 \mathrm{~m}$ sucrose in MS medium, for $20 \mathrm{~min}$ at room temperature.
Then, the meristems were exposed to PVS2, containing $0.4 \mathrm{~m}$ sucrose, $30 \% \mathrm{v} / \mathrm{v}$ glycerol, $15 \% \mathrm{v} / \mathrm{v}$ ethylene glycol and $15 \%$ dimethyl sulfoxide in MS medium, at $0{ }^{\circ} \mathrm{C}$ for 10 , 20, 30, 45, and $60 \mathrm{~min}$. Subsequently, the meristems were placed on sterile aluminium foil strip $(20 \mathrm{~mm} \times 5 \mathrm{~mm})$ in a droplet of PVS2. Each strip was then plunged directly into $\mathrm{LN}$ and quickly transferred into a $2 \mathrm{ml}$ cryovial filled with LN for $1 \mathrm{~h}$.

Rewarming was performed by rapid plunging the aluminium strip into recovery solution (RS), containing $1.2 \mathrm{~m}$ sucrose in MS medium, at room temperature for $15 \mathrm{~min}$. Unloaded meristems were placed on sterile filter paper plated on solid MS medium, containing $0.3 \mathrm{~m}$ sucrose for 1 day and then subcultured to a solid MS medium, containing 60 or $90 \mathrm{~g} \mathrm{l}^{-1}$ sucrose, respectively. The cultures were maintained in the dark for 10 weeks at $20 \pm 2{ }^{\circ} \mathrm{C}$.

Control meristems were treated with all the solutions, but not immersed in LN.

The survival rate was determined 2 weeks after rewarming. Some of the surviving apices started callusing within 2 weeks. Regrowth was determined 10 weeks after rewarming.
Fig. 1 Excised apex before cryopreservation (a); surviving apex 2 weeks after cryopreservation (b); dead apex (c); callusing apex (d); regenerating apex into bulblets: 6 weeks after cryopreservation (e), 10 weeks after cryopreservation (f). Cryopreservation treatments: $60 \mathrm{~g}$ $1^{-1}$, cold treatment and $30 \mathrm{~min}$ exposure to PVS2 (b, e); $90 \mathrm{~g}$ $1^{-1}, 10$ min exposure to PVS2 (c); $60 \mathrm{~g} \mathrm{l}^{-1}, 20 \mathrm{~min}$ exposure to PVS2 (d); $60 \mathrm{~g} \mathrm{l}^{-1}$, cold treatment and 60 min exposure to PVS2 (f). Bars: $1000 \mu \mathrm{m}$
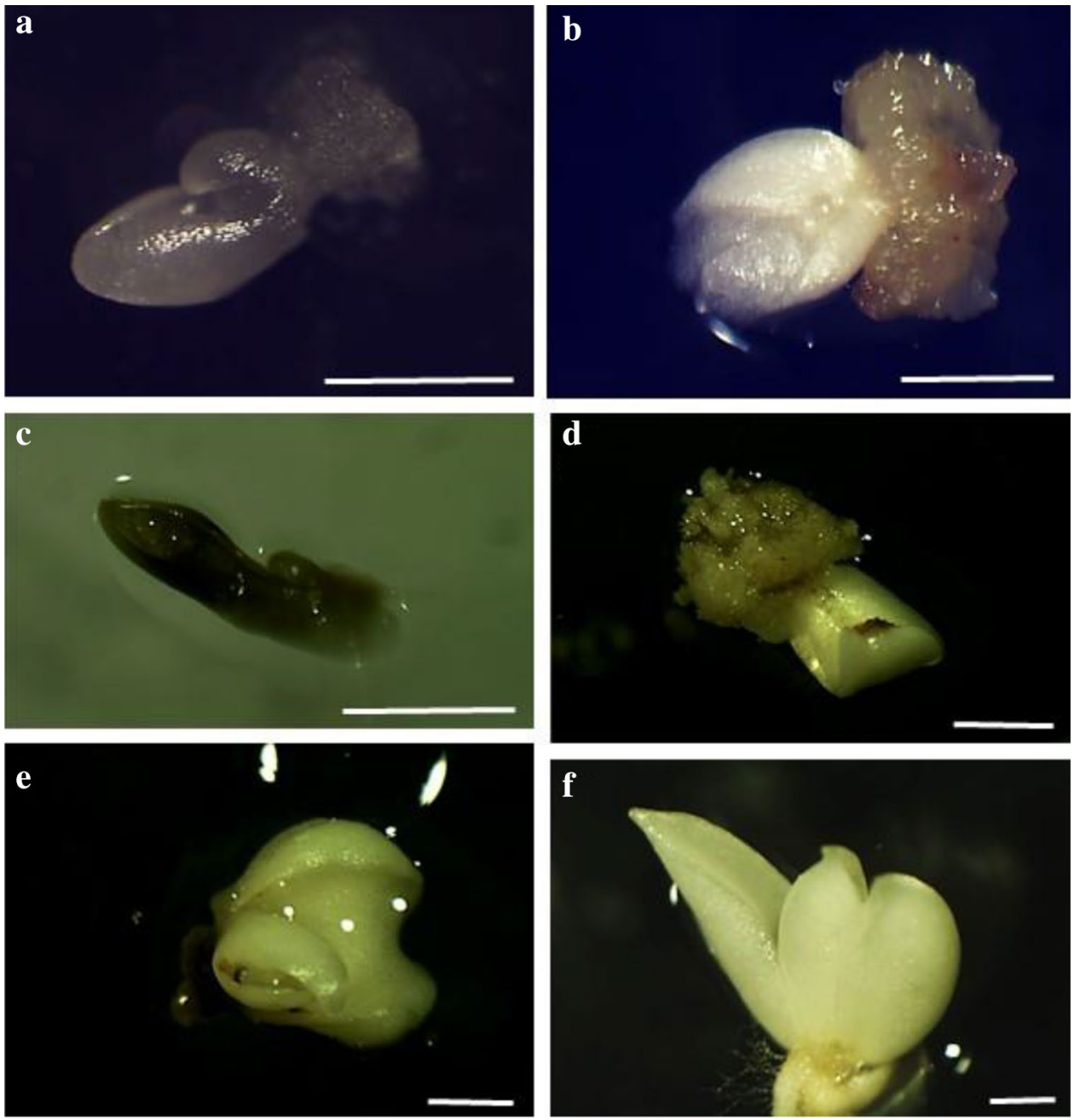
Ten apical meristems were used in each of five replicates. The percentage data (arcsine transformed) were subjected to ANOVA using Statistica 13 software (StatSoft). Comparisons of mean values were made with Duncan's test at a significance level of $\mathrm{p} \leq 0.05$.

Surviving meristems show a whitish or translucent appearance (Fig. 1b). Dead apices became brown (Fig. 1c) with no sign of regrowth. Regeneration of control meristems ranged between 50 and $100 \%$ but no clear correlation can be observed between PVS2 treatment length, cold treatment and regeneration (Fig. 2a). After cryopreservation, $100 \%$ survival was observed among cold treated explants from medium with $60 \mathrm{~g} \mathrm{l}^{-1}$ sucrose, after 20, 30 and 60 min treatment of PVS2 (Fig. 2b).

Three weeks after thawing a slow growth of the meristems (enlarging in size) could be observed and after about 6-10 weeks bulb scale and then bulblets started forming (Fig. 1e, f). One hundred percent regrowth was obtained from cold treated apices cultured on $60 \mathrm{~g}^{-1}$ sucrose, followed by 30 and 60 min PVS 2 treatment. Cold treatment significantly improved the recovery rates of all cryopreserved apical meristems cultivated on medium with $60 \mathrm{~g}$ $1^{-1}$ sucrose. The positive effect of cold treatment was especially observed with 20-30 min of PVS2 treatment, since four times more regenerating plants were obtained (Fig. 2b). Similar results (for 20-30 min of PVS2 treatment) were obtained for the media containing $90 \mathrm{~g}^{-1}$ sucrose. Ten minutes of PVS2 exposure was inadequate for sufficient dehydration of the apices, which resulted in no significant regrowth. Regrowth of cryopreserved, noncold treated meristems, both from 60 to $90 \mathrm{~g} \mathrm{l}^{-1}$ sucrose, increased gradually with increasing length of PVS2 exposure and reached maximum after 60 min exposure (74\% and $70 \%$, respectively). Therefore, PVS2 exposure duration, not sucrose concentration, is the factor which most affects meristem regrowth (Fig. 2b).

Three-to-four weeks after rewarming, some surviving meristems covered with undifferentiated, yellowish callus (Fig. 1d). The highest percentage of callusing (60-68\%) was noted after 10-30 min of PVS2 exposure of non-cold treated meristems from $60 \mathrm{~g}^{-1}$ sucrose for cryopreserved meristems. In other cryopreservation treatments, the callusing rate did not exceed 20\% (Fig. 2b).

In this study a cryopreservation protocol based on droplet-vitrification technique was developed that allowed successful plant regeneration from apical meristem of Tulipa tarda. To optimize the protocol, different treatments and immersion times in PVS2 were studied.

Cryopreservation success depends on explant type, age and size, its physiological condition, acclimation to osmotic stress and cold conditions at every step of the treatment (Kim et al. 2009; Harding et al. 2009).

The executed experiment shows that it is possible to achieve $100 \%$ regeneration of $T$. tarda apices after appropriate treatment by sucrose $\left(60 \mathrm{~g} \mathrm{l}^{-1}\right)$ and cold treatment $\left(5^{\circ} \mathrm{C}\right)$, followed by 30 or 60 min PVS2 treatment. It is probably,
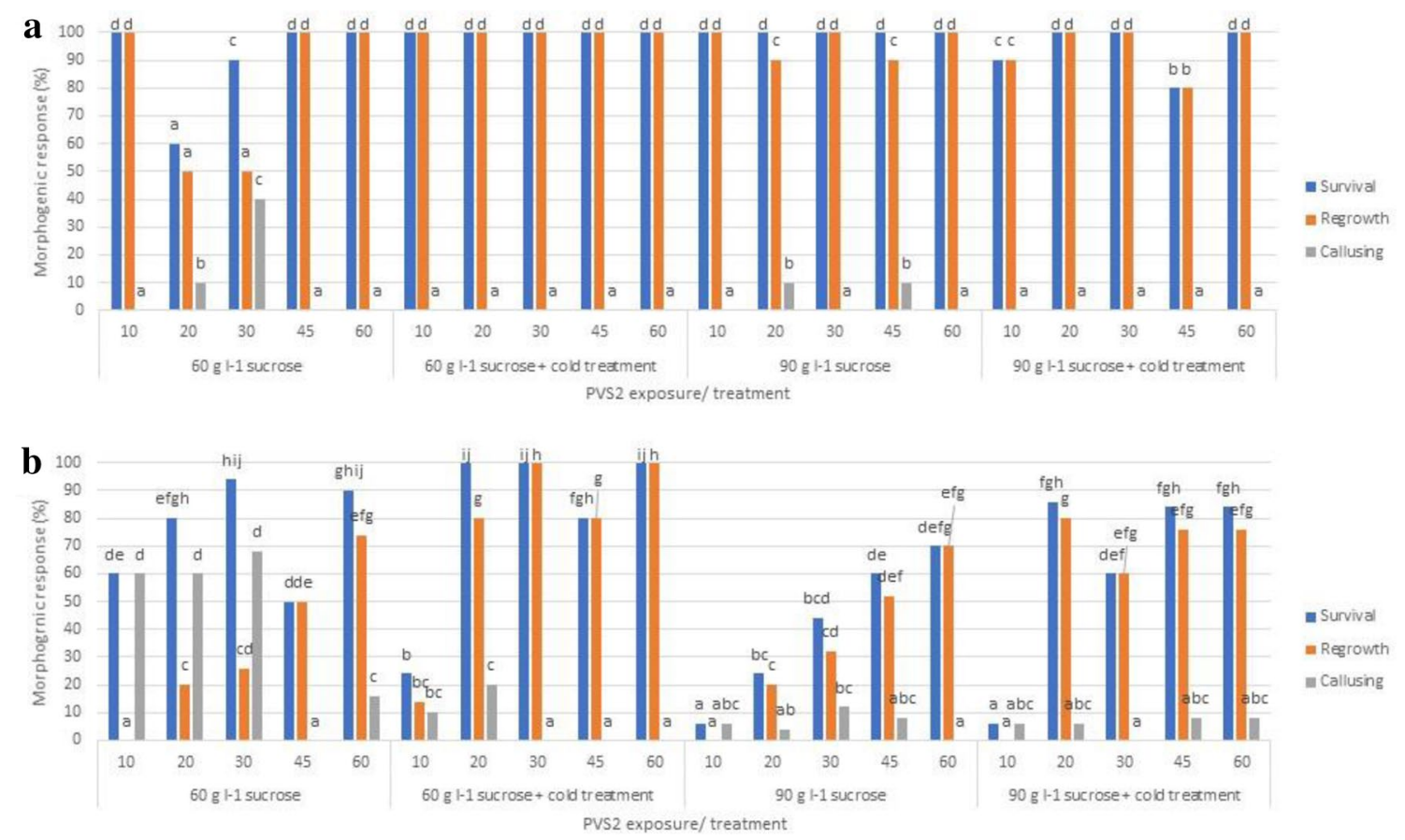

Fig. 2 Regeneration of non-cryopreserved (a) and cryopreserved (b) apical meristems. Means within a columns followed by the same letter are not significantly different at $p \leq 0.05$ 
that significantly lower regeneration (80\%) in case of $45 \mathrm{~min}$ PVS2 treatment could result in number of replicates. It is likely that the differences will not be significantly different when applying much more apices. There was not observed an improvement of regrowth rates using a higher sucrose concentration. Authors hypothese that $60 \mathrm{~g} \mathrm{l}^{-1}$ sucrose was high enough to acquire a sufficient degree of dehydration resistance. It is important to prepare tissue towards dehydration using a sugar and/or cold treatment and by optimizing time of exposure to cryoprotective solutions for each species (Panis and Lambardi 2006). Pre-cryopreservation treatments like osmotic or cold treatments, followed by the application of cryoprotective solutions, allowed for successful cryopreservation of many plants (Reed 2017). Cold pretreatment prepare explants to cryopreservation by activation of signaling pathways and alteration of gene expression. Cold exposure induces the synthesis of osmo-active compounds, like fructose and glucose, related to freezing tolerance, suggesting that cold acclimation is associated with an altered carbohydrate metabolism (Rosa et al. 2009). Preculture with sucrose $(0.3 \mathrm{M})$ in combination with cold-hardening of in vitro meristems $\left(\right.$ at $0{ }^{\circ} \mathrm{C}$ ) or plantlets $\left(\right.$ at $4{ }^{\circ} \mathrm{C}$ ) proved to be essential for successful cryopreservation of Lilium shoot tips (Matsumoto et al. 1995; Chen et al. 2011). However, in case of in vitro shoot apices of Oxalis tuberosa, cold treatment did not improved survival rate (Gonzáles-Benito et al. 2007). Some researchers obtained high recovery rate of the apices of Galanthus (75.5\%) and Lilium (87.5\%) applying only high sucrose concentration, without cold-hardening (Maślanka et al. 2013; Yin et al. 2014).

In view of the risk for somaclonal variation, the recovery processes after cryopreservation should preferably not occur through adventive shoot formation or organogenesis. Nevertheless, sometimes callusing appears as an effect of cryoinjury. In our study $60-68 \%$ of callusing explants might be a result of an insufficient preparation of the tissue towards dehydration (both by treatment and vitrification) before plunging in LN. Cold treatment of the tissue prior to cryopreservation resulted even $100 \%$ of non-callusing bulblets after thawing. Callusing of the apices after cooling was also observed in Galanthus (Maślanka et al. 2013) and Lilium (Bouman et al. 2003).

Acknowledgements This study was financed by Polish Ministry of Science and Higher Education (3500/KRO).

The authors thank dr Bart Panis for helpful feedback on this document.

Open Access This article is licensed under a Creative Commons Attribution 4.0 International License, which permits use, sharing, adaptation, distribution and reproduction in any medium or format, as long as you give appropriate credit to the original author(s) and the source, provide a link to the Creative Commons licence, and indicate if changes were made. The images or other third party material in this article are included in the article's Creative Commons licence, unless indicated otherwise in a credit line to the material. If material is not included in the article's Creative Commons licence and your intended use is not permitted by statutory regulation or exceeds the permitted use, you will need to obtain permission directly from the copyright holder. To view a copy of this licence, visit http://creativecommons.org/licenses/by/4.0/.

\section{References}

Botschantzeva ZP (1982) Tulips. Taxonomy, morphology, cytology, phytogeography and physiology. A. A. Balkema, Rotterdam

Bouman H, Tiekstra A, Petutschnig E, Homan M (2003) Cryopreservation of Lilium species and cultivars. Acta Hortic 612:147-154

Chen X-L, Li J-H, Xin X, Zhang Z-E, Xin P-P, Lu X-X (2011) Cryopreservation of in vitro-grown apical meristems of Lilium by droplet-vitrification. South Afri J Bot 77:397-403

Engelmann F, Dussert S (2013) Cryopreservation. In: Norman MN, Chin HF, Reed BM (eds) Conservation of tropical plant species. Springer, New York, pp 107-119

Gonzáles-Benito ME, Clavero-Ramírez I, López-Aranda JM (2004) The use of cryopreservation for germplasm conservation of vegetatively propagated crops. Span J Agric Res 2:341-351

Gonzáles-Benito ME, Mendoza-Condori VH, Molina-Garcia AD (2007) Cryopreservation of in vitro shoot apices of Oxalis tuberosa Mol. CryoLetters 28:23-32

Harding K, Johnston JW, Benson E (2009) Exploring the physiological basis of cryopreservation success and failure in clonally propagated in vitro crop plant germplasm. Agric Food Sci 18:103-116

Keller ERJ, Kaczmarczyk A, Senula A (2008) Cryopreservation for plant genebanks: a matter between high expectations and cautious reservation. CryoLetters 29:53-62

Kim HH, Lee JK, Hwang HS, Engelmann F (2007) Cryopreservation of garlic germplasm collections using the droplet-vitrification technique. CryoLetters 28:471-482

Kim HH, Lee YG, Shin DJ, Ko HC, Gwag JG, Cho EG, Engelmann F (2009) Development of alternative plant vitrification solutions in droplet-vitrification procedures. CryoLetters 30:291-299

Li JW, Zhang XC, Wang MR, Bi WL, Faisal M, Teixeira da Silva JA, Volk GM, Wang QC (2019) Development, progress and future prospects in cryobiotechnology of Lilium spp. Plant Methods $15: 125$

Maślanka M, Bach A (2013) Cryopreservation of Tulipa tarda Stapf. apical meristems by droplet vitrification. Acta Biol Crac 55:58

Maślanka M, Panis B, Bach A (2013) Cryopreservation of Galanthus elwesii Hook. apical meristems by droplet vitrification. CryoLetters $34: 1-9$

Maślanka M, Panis B, Malik M (2016) Cryopreservation of Narcissus L 'Carlton' somatic embryos by droplet vitrification. Propag Ornam Plants 16:28-35

Matsumoto T, Sakai A, Yamada K (1995) Cryopreservation of in vitrgrown apical meristems of lily by vitrification. Plant Cell Tiss Org Cult 41::237-241

Murashige T, Skoog F (1962) A revised medium for rapid growth and bioassays with tobacco tissue culture. Physiol Plant 15:473-497

Panis B, Lambardi M (2006) Status of cryopreservation technologies in plants (crops and forest trees). In: Ruane J, Sonnino A (eds) The Role of Biotechnology for the Characterisation and Conservation of Crop, Forestry, Animal and Fishery Genetic Resources. Food and Agriculture Organization of the United Nations, Roma, pp $61-78$ 
Panis B, Piette B, Swennen R (2005) Droplet vitrification of apical meristems: a cryopreservation protocol applicable to all Musaceae. Plant Sci 168:45-55

Pawłowska B, Szewczyk-Taranek B (2015) Efficient cryopreservation by droplet vitrification of pentaploid roses and the phenotype of regenerated plants. Acta Soc Bot Pol 84:439-442

Reed BM (2017) Plant cryopreservation: a continuing requirement for food and ecosystem security. In Vitro Cell Dev Biol-Plant 53:285-288

Rosa M, Prado C, Podazza G, Interdonato R, Gonzalez JA, Hilal M, Prado FE (2009) Soluble sugars-metabolism, sensing and abiotic stress. Plant Signal Behav 4:388-393

Sakai A, Kobayashi S, Oiyama I (1990) Cryopreservation of nucellar cells of navel orange (Citrus sinensis Osb. var. brasiliensis Tanaka) by vitrification. Plant Cell Rep 9:30-33

Sant R, Panis B, Taylor M, Tyagi A (2008) Cryopreservation of shoottips by droplet vitrification applicable to all taro (Colocasia esculenta var. esculenta) accessions. Plant Cell Tiss Org Cult 92:107-111

Schäfer-Menuhr A, Schumacher HM, Mix-Wagner G (1997) Cryopreservation of potato cultivars - design of a method for routine application in genebanks. Acta Hortic 447:477-482

Wang QC, Panis B, Engelmann F, Lambardi M, Valkonen JPT (2009) Cryotherapy of shoot tips: a technique for pathogen eradication to produce healthy planting material and for cryopreservation of healthy plant genetic resources. Ann Appl Biol 154:351-363

Urbaniec-Kiepura M, Bach A (2017) Cryopreservation of Lilium martagon L. meristems by droplet-vitrification and evaluation of their physiological stability. Cryoletters 38:78-89

Yin ZF, Bi WL, Long C, Zhao B, Volk GM, Wang QC (2014) An efficient, widely applicable cryopreservation of Lilium shoot tips by droplet-vitrification. Acta Physiol Plant 36:1683-1692 